\section{Principios para una ética de la ficción televisiva}

Roberto Aras *

\begin{abstract}
Resumen: El panorama general de la ficción televisiva justifica que se hable de ella en términos de perplejidad moral y valorativa. Sin embargo, a pesar de la enorme dispersión de enfoques y miradas sobre los problemas humanos que se exponen en las pantallas, casi todos comparten el estilo de un alto compromiso emotivo y poca demanda crítica.

Una perspectiva moral renovadora requiere, pues, tomar conciencia de la alta incidencia de los modelos presentes en los relatos audiovisuales para incorporar en su creación, guión, edición y producción, los principios capaces de elevar la responsabilidad sobre el perfil de esos productos. Así los Principios de no Instrumentalización, de Hospitalidad, de Credibilidad y de Tolerancia aparecen como los caminos posibles para comenzar a mejorar el nivel ético de la programación.
\end{abstract}

Palabras clave: credibilidad - ética - ficción - hospitalidad - instrumentalización - principios televisión - tolerancia.

[Resúmenes en inglés y portugués en las páginas 190-191]

${ }^{(*)}$ Doctor en Filosofía (Universidad de Navarra, 2004). Licenciado en Filosofía (UCA, 1987). Profesor Titular Ordinario en la Pontificia Universidad Católica Argentina en el Instituto de Ciencias Políticas (ICPRI) y en el Instituto de Comunicación Social (ICOS). Secretario Académico de la Facultad de Ciencias Sociales, Políticas y de la Comunicación de la Universidad Católica Argentina.

Con el advenimiento de la anunciada "aldea global", no sólo el sistema de las comunicaciones se ha convertido en la red neurálgica de casi todos los intercambios socio-económicos y culturales sino que ciertos contenidos se han afianzado como productos de consumo planetario. La televisión representa dentro de este sistema el medio más ubicuo ya que, si bien antes la encontrábamos en el centro de los hogares, ahora aparece incorporada a los servicios que se ofrecen en la telefonía celular o en otros dispositivos personales, al tiempo que también se afirma como el medio más flexible, pues admite desde la emisión de programas grabados hasta la transmisión en vivo. La televisión, entonces, frente a las demás formas de comunicación audiovisual adquiere una prioridad que se justifica por las características aludidas y que se expresa en la cantidad de horas que la población mundial pasa frente a la pantalla.

Esta situación, ciertamente hegemónica, lejos de haberse perdido con el surgimiento de Inter- 
net se ha potenciado bajo una nueva alternativa de distribución, que además le agrega una inédita posibilidad de interacción con las audiencias ${ }^{1}$. Más aún, la creciente facilidad técnica para que el usuario/televidente pueda generar por sí mismo productos audiovisuales e incorporarlos al flujo general que circula por la red, ha multiplicado las oportunidades de intervención de aquellos que no estaban incluidos en el campo profesional de la televisión.

La explosión audiovisual en Internet ha revelado así, de manera incontrovertible, la importancia que en la vida de las personas posee esa dimensión de la comunicación tanto para la adquisición de información y noticias, como para el entretenimiento o la expresión de la propia opinión. Sin embargo, con ánimo de simplificación podríamos reducir a dos los formatos en que esas funciones buscan cumplirse: el informativo (que incluye los telediarios, documentales, programas culturales y deportivos, entrevistas de diversa índole y algunos que caen bajo el rótulo de true-television), y la "ficción" (donde se agrupan las telenovelas, teleseries, dibujos animados, programas de humor, etc.), o como lo resume José Cortés (1999) "aquéllos que tienen que ver directamente con la realidad misma en sí y aquellos que tienen que ver con lo inventado o reinventado" (Cortés, 1999, p. 152).

Ahora bien, en ese panorama que abarca la extensa influencia de la televisión -muy por encima de la que se le pudiera atribuir al cine- a causa de su accesibilidad, gratuidad (al menos en un segmento de la programación) y variedad, la ficción es la que ha motivado un menor número de reflexiones éticas. La función informativa, por su parte, fue subsumida en las investigaciones sobre la ética periodística y rápidamente ganó un espacio propio en la bibliografía especializada. Esta realidad, sin embargo, tiende a cambiar y en los últimos años se ha visto un aumento de los estudios sobre la ficción en televisión atendiendo, en particular, al fenómeno de la multiplicación de los circuitos comerciales que colocan, en los mercados más distantes, obras construidas para un público estandarizado que disfruta tramas imaginarias que nada tienen que ver con su realidad cotidiana o con su manera de entender culturalmente los vínculos humanos ${ }^{2}$. Asimismo, se han extendido los estudios que profundizan el análisis de la retórica involucrada en la comunicación audiovisual, el pensamiento narrativo, la equivalencia y mixtura de géneros, la influencia de ciertos tópicos centrales -como la violencia- o la construcción de las audiencias. Todos ellos son temas que admiten un tratamiento ético y una discusión sobre sus consecuencias en la formulación de la identidad personal o colectiva de los televidentes.

En las próximas páginas pretendo contribuir a ese debate -todavía incipiente- con una reflexión sobre los principios que deberían regular el desarrollo de la ficción televisiva permitiendo a todos los agentes involucrados en su realización una mayor conciencia ética y, por tanto, un ejercicio de su responsabilidad más lúcido y coherente.

\section{1. Ética para un ser simbólico}

En la obra An Essay on Man (1944)3, Ernst Cassirer, sin negar la racionalidad humana como constitutiva del hombre (así ya lo había establecido Aristóteles) pretende superar esa definición afirmando que la esencia de lo humano queda mejor establecida cuando se acepta que describe a un "animal simbólico". En efecto, en continuidad con el texto de su Filosofía de las formas simbólicas (1971), el pensador alemán sostiene que el sistema de los símbolos actúa como mediador entre la interioridad significante y la exterioridad del mundo y sus configuraciones. Por 
eso el hombre no trata con las cosas como si fueran entes completamente heterogéneos, pues interpone entre ellas y su mismidad un medio artificial que los aglutina y articula, y que llamamos cultura: los códigos lingüísticos, las imágenes artísticas, el rigor científico, las historias míticas o los ritos religiosos son los canales que constituyen la experiencia humana y le permiten expresarse en el espacio simbólico de la civilización.

Ahora bien, los símbolos suponen, junto con una apelación a la inteligibilidad, el reconocimiento de una dimensión sensible de la cual no se puede prescindir. En el terreno de la ética, esta condición del símbolo refiere también a la integración de la dualidad somato-psíquica en la conducta y a la percepción como camino de contacto con los otros, hacia quienes se dirige en primer lugar el deber moral. Incluso el devenir de un sistema simbólico aprendido supone la integración de un "yo" (presente) que le habla a un "tú" (co-presente) respecto de un "él" (ausente, a quien se re-presenta), articulados, fundamentalmente, en el proceso de la comunicación verbal (Dufour, 2007).

Esta perspectiva bien puede alinearse con el pensamiento de Georg Simmel para quien la exigencia ética nace de la fidelidad a la vida individual y de nuestra responsabilidad frente a esa totalidad del yo viviente que no puede excluir a sus semejantes para dar sentido a su vida. En esta concepción, sin embargo, no hay un «otro» que imponga un precepto supraindividual o transindividual o que establezca a priori las normas desde una autonomía abstracta y universal, sino que son las demandas del vivir-con las que terminan modelando mi capacidad para iluminar un itinerario ético en el seno de la sociedad. Ortega y Gasset, reformulando a Simmel, defiende que el imperativo ético esencial es el deber de dar a la propia vida su plenitud y perfección, pero reconoce que sería un ideal vacío si no aceptáramos que necesita realizarse en la con-vivencia con nuestros semejantes. "El individuo moral es el que asume la responsabilidad de sus actos y la obligación primaria de cuidar al otro" (Silverstone, 2010, p. 226) como una expresión del acercamiento que exige el trato auténticamente humano (la observación del rostro que sugiere E. Levinas) y que en la vida social -en particular la que reúne a través de los massmedia- queda muchas veces suspendido por la distancia que impide la interpelación personal. La ética se constituye, así, en una disciplina que nos propone alcanzar la vida buena observando ciertas prácticas que ordenan las potencialidades que poseemos hacia aquellos fines adecuados para nuestra naturaleza y por medio de las cuales alcanzamos el autodominio, es decir, la capacidad de no entregarnos a metas subalternas para poder conquistar los objetivos de vida a los cuales apuntamos. Pero, puesto que somos seres sociales, gran parte de nuestras acciones implican a otras personas y es gracias a la posibilidad de permutar lugares con ellas que sabemos hasta qué punto colaboran u obstaculizan nuestro proyecto vital.

En el caso de las representaciones audiovisuales, la aparición sensible del "otro" queda doblemente mediatizada: en la situación que plantea el conflicto de la trama y en la inducción que facilita, junto con otras representaciones, para la íntima elaboración de un significado ético. De esta manera, la potencia del ejemplo también se duplica a partir de la unión del pensamiento abstracto con la síntesis audio-visual que es apta para transmitir modelos de preferencia, e incluso, de excelencia moral.

En el mismo sentido, Paul Ricoeur (2000) se refiere a la ficción como poseedora de un efecto de referencia por el cual tiene el poder de redescribir la realidad y por eso "la paradoja de la ficción es que la anulación de la percepción condiciona un aumento de nuestra visión de las cosas" (Ricoeur, 2000, p. 205). En otras palabras, la ficción introduce por vía de la imaginación 
una nueva potencia configuradora que resignifica las categorías de espacio, tiempo y persona, y abre un espacio de libertad simbólica indispensable para lanzarse a la acción.

Ahora bien, si las referencias simbólicas son básicas a la hora de interpretar la actuación de los demás y nuestra propia conducta, pero con la condición de realizar una decodificación discursiva previa, ¿cómo influye en el éxito de este proceso la interposición de "prótesis sensoriales" (Dufour, 2007), como la televisión, que inhiben al sujeto-filtro por su alta demanda de adhesión sensible? ¿Qué sucede, entonces, con las ficciones audiovisuales que se constituyen en mundos autocontenidos y cuya asimilación crítica se hace, con cada generación, menos habitual, hasta plantearnos la posibilidad de su extinción total?

De aceptar lo que plantea Salomon (2010) de que "actualmente las masas sociales por estar interactivamente unidas comunicativa e informativamente, consideran a los modelos visuales prototípicos como los cuadrantes formales de su vida particular y social" (Salomon, 2010, p. 270), es urgente identificar y explicitar los principios éticos que regulan la construcción de esos modelos y proponer criterios que favorezcan la autonomía conceptual para valorarlos.

\section{Televisión y consumo}

Uno de los debates más extendidos en el ambiente académico -y en la tribuna política- se da en torno a la calidad y pluralidad audiovisual, y sitúa a la televisión en el centro de la controversia. ¿Qué tan lejos está la programación existente de los ideales de excelencia en la producción de contenidos? ¿Somos tratados como una audiencia inteligente a la cual hay que proveer de productos inteligentes? ¿Es todo lícito a la hora de generar distracción para un público cada día menos dispuesto para la argumentación discursiva?

Ciertamente la dimensión comercial de la televisión impulsa una preocupación sostenida para lograr niveles de audiencia cada vez mayores y promueve, por ello, la aparición de fórmulas de éxito de cuestionable moralidad. Una de ellas es la emocionalidad espectacularizada (Gozálvez, 2004) en la que la búsqueda de la extroversión, la publicidad de la intimidad y la captura de imágenes de alto impacto emotivo son puestas al servicio de cualquier mensaje informativo. Manuel Castells (1999) halló otra de esas fórmulas en la simpleza y ambivalencia de las imágenes, que admiten plásticamente la organización ideológica que las audiencias proyecten sobre ellas. Sin embargo, me atrevería a sugerir que es la hiperrealidad de los medios la cualidad que intensifica todos los demás factores que intervienen en los patrones mencionados, pues la suplantación que ejecuta vacía de dramatismo la vida cotidiana y la sustituye por su representación estéticamente controlada. Se sigue, entonces, que la verdadera realidad sucede en la pantalla y sólo la transposición de sus códigos a la existencia individual provee a ésta del híbrido necesario para dotarla de verosimilitud y consistencia.

Es indudable que la necesidad de construir audiencias para sostener la programación favorece el tratamiento del espectador como un objeto comercial y plantea una dialéctica de supervivencia de la que el rating es su expresión más cruel y constante.

En el terreno ético, la fórmula consumo=masividad +rating produce consecuencias devastadoras: en primer lugar, atenta contra el "principio de no instrumentalización" (Cortina, 2004) 
al asumir que las personas sólo importan como puntos estadísticos en la consulta del minuto a minuto; por otra parte, la pretensión de lograr una respuesta impulsiva y estereotipada para mejorar los índices de audiencia es un ejercicio que tiende a disminuir la libertad del espectador y no a incrementarla; finalmente, la tendencia a favorecer una mayor implicación emocional del espectador impone en los medios una responsabilidad difícil de sostener sin un compromiso ético declarado de respecto y escucha a la voz del usuario.

Precisamente, a partir de que "las necesidades de interacción y emotividad no quedan cubiertas en la sociedad contemporánea y se buscan en el consumo televisivo" (Huertas Bailén, 2002. p. 116) asoma a través de la cultura mediática una nueva generación de mitos que contienen "los valores fundamentales de la sociedad que el individuo registra en su memoria y utiliza como guía en otras situaciones semejantes" (Lacalle, 2001, p. 39).

Así, "memorizadas u olvidadas, las imágenes (...) forman parte de nuestra experiencia del mundo que, sin duda, cada uno de nosotros integramos a nuestra manera, en función de nuestra historia y de su condicionamiento" (Joly, 2003, p. 279) y reelaboramos muchas veces a la luz de los relatos ficcionales.

Ahora bien, para que las configuraciones míticas tengan efectividad en el repertorio de preferencias y postergaciones que regulan los comportamientos colectivos, es necesario que se verifique "una mayor proximidad entre lo que se ve y lo que se vive" (Huertas Bailén, 2002, p. 119). Así, los personajes de las telenovelas se convierten en seres anónimos, de cualidades grises y tipología estándar, que habitan mundos cercanos y que favorecen la identificación antes que la imitación. Ya no es la excelencia del protagonista lo que mueve a la admiración y al seguimiento, sino el incremento de la autoestima que provoca el descubrirse empáticamente como reflejo del personaje televisivo. De ahí su capacidad de influir en la audiencia pues la acompañan y se relacionan con los sujetos que la conforman mediante un trato cuasi-familiar, apto para derrumbar las barreras de la distancia mediática. Por eso la asimilación de virtudes y vicios -pero también de impulsos y hábitos de consumo-, e incluso de una cierta estilización del comportamiento, deviene una consecuencia natural de la exposición a la pantalla.

Sin embargo, a pesar de las conclusiones apresuradas que a veces se obtienen del análisis de aquellos procesos identificatorios (tal como sucede con la cuestión de la violencia, o de la agresividad), hay que advertir que no conviene aceptar una teoría monocausal o de dirección única cuando se pretende explicar la referencialidad de las acciones privadas hacia los modelos presentados por la televisión. Los estudios más serios en esta materia proponen distinguir entre los contenidos reales o ficticios de las emisiones y la percepción (real o ficticia) que sobre ellos posee el televidente para determinar luego su influencia efectiva en los niveles cognitivo y conductual (García Galera, 2000, p. 129).

Aún con la prudencia que sugieren las palabras anteriores, podemos aceptar que "los lenguajes y los marcos de sentido de la cotidianeidad y de la ficción son intercambiables" (Peñamarín, 2005 , p. 354) y la justificación proviene de los estudios etnográficos que han mostrado la comunicación que existe entre lo que sucede en los episodios de ficción y los acontecimientos ocurridos en entornos no ficticios, de manera que los primeros son comentados en la perspectiva que abren los segundos y éstos se utilizan como modelos cognitivos para interpretar lo que sucede en los problemáticos mundos de vida de cada cual. 


\section{Conflictos éticos en la ficción}

El diccionario de la lengua castellana define "ficción" como "la acción y efecto de fingir, invención imaginaria o creación poética" (Casares, 1975) pero el uso del término en la televisión proviene del inglés (fiction) y sirve para nombrar uno de los dos mundos en que se dividen los contenidos televisivos (fiction / non fiction). Sin embargo, si atendemos a la raíz latina, "la primera acepción de fingere no es "fingir" sino "forjar". La ficción es la construcción, por medios artísticos, de un sistema de acciones representadas, de formas ensambladas, de signos que se responden" (Rancière, 2005, p. 182). El propósito de la ficción, entonces, queda determinado por la producción imaginaria de un espacio asimétrico de verosimilitudes. Ahora bien, si como quedó establecido en el punto anterior, "la narración de ficción construye un modelo análogo del universo vital, lo que permite, como en todos los modelos, conocer la estructura y los procesos internos de la realidad y manipularla cognitivamente" (Peñamarín, 2005, p. 344), es indudable que la perspectiva ficcional contribuye así a desarrollar competencias mentales y representacionales que son usadas, luego, para intervenir en la vida real.

Esa ejemplificación de situaciones que "son susceptibles de ser interiorizadas por inmersión y que, eventualmente, pueden ser reactivadas de manera asociativa" (Schaeffer, 1999, pp. 47, 76) constituyen un intento por anticipar problemas, por esclarecer y por reducir la incertidumbre en los conflictos habituales de la existencia.

Se comprende ahora por qué es relevante establecer los principios de una ética de la ficción televisiva que promuevan, por una parte, una manera de producir contenidos que sea conciente de la influencia que ejercen los mismos sobre la audiencia, y por otra, "frente al hábito de la audiovisión pasiva, la ética celebra la voluntad selectiva y la educación para la libertad mediática" (Gozálvez, 2004, p. 229) que consolidan la autonomía y la participación crítica.

En este punto hemos cruzado la línea que separa el debate ético clásico vinculado con temas como "los derechos de propiedad de las imágenes grabadas, el derecho a saber frente al derecho a la intimidad, las responsabilidades del realizador con respecto a su tema y su público, o su jefe" (Nichols, 1997, p. 117) entre otras cuestiones, y avanzamos hacia una mirada más centrada en las obligaciones que en los derechos, pues sólo en función de lo que se «debe hacer» queda establecida una concepción del bien o de la virtud (Silverstone, 2010, p. 232).

Por ello, la exploración de los valores relevantes para la solución de un conflicto ético conduce a un análisis de la situación que no se agota en la nominación de derechos -cuyos sujetos en litigio son siempre individuales- $y$, en cambio, involucra una responsabilidad que pertenece a todos los actores del contexto social en el que sucede y que los mueve a preocuparse por las condiciones que hacen posible la misma comunicación en sentido integral.

Esta perspectiva se hace cargo de la complejidad dinámica que es todo proceso comunicativo y de la necesidad de afrontarlo desde la esfera pública de los valores para no reducir el espacio moral a categorías inter-individuales. La necesidad de contar con los medios que la sociedad globalizada exige para casi todas las transacciones (ya aludimos a la visión de la realidad que la televisión se encarga de construir y que actúa como un orden espontáneo que se interpone a los acontecimientos) genera, correlativamente, un compromiso de vigilancia que excede la esfera de las acciones particulares y llega hasta la estructura de la sociedad civil democrática. En la medida en que las mediatizaciones son un ingrediente inseparable de nuestra vida diaria, 
"se vuelve decisiva la cuestión relativa a la manera en que los medios nos sitúan o permiten situarnos" (Silverstone, 2010, p. 253).

Tomemos un ejemplo para el ámbito de la no-ficción: el uso de cámaras ocultas o micrófonos para inmiscuirse en la vida de un sujeto cualquiera quien, gracias a la mediación tecnológica, es expuesto a la vista y al juicio de millones de ciudadanos (con su aceptación o complicidad como en el caso de "Gran Hermano"-, o sin ella), no sólo es una transgresión al derecho básico a la intimidad que podría reclamar el personaje bajo observación, sino que plantea una interpelación a todos los que a través de esas prácticas de deshumanización traicionan la confianza en el semejante o someten a la posibilidad de una amenaza anónima y secreta el contenido de la vida propia que escapa a la opinión pública. No basta, entonces, con concebir el espionaje mediático como un atentado a la intimidad de un ser humano sino que hay que estimarlo como el decreto de vulnerabilidad (la puesta en peligro) que hace una comunidad a la capacidad de resguardo de uno de los pilares de la convivencia social, con similar grado de perjuicio para todos los que la componen.

Pensemos ahora en otro tema que ha sido objeto de numerosos estudios morales en el campo de la información y el documentalismo: la muerte. Hay suficientes advertencias en los códigos deontológicos respecto de las condiciones en que una muerte puede ser difundida: el registro de muertes accidentales en actuaciones deportivas, en general, no son publicadas o se emiten con una advertencia previa, algo similar sucede con los suicidios, y en las guerras que se han seguido mediante transmisiones desde la línea de fuego estuvo prohibido fotografiar cadáveres. El respeto a la dignidad de las personas fallecidas, la sensibilidad hacia sus familiares y amigos para impedir que las imágenes les generen situaciones traumáticas, y el balance entre la noticia (que supera el caso individual) y el impacto emotivo, han actuado como los controles a la hora de evaluar la conducta a seguir.

Sin embargo, el análisis es muy diferente cuando entramos en el universo de la ficción. "La muerte en la ficción se experimenta como algo visible" (Nichols, 1997, p. 120), cuando no se utilizan recursos icónicos o simbólicos para simplemente aludirla. En casi todas las telenovelas, la muerte de alguno de los protagonistas es un punto de inflexión en la historia. ¿Cuál es el conflicto ético que puede aparecer en la representación de la muerte?

En rigor, las posibilidades se multiplican de acuerdo con el acontecimiento argumental que haya desencadenado la defunción. A menudo, los libretistas utilizan un suicidio al cual rodean de una cierta tonalidad romántica; otras veces, se trata de un asesinato que ha sido cuidadosamente planificado; y por último, tampoco está ausente la muerte que se produce en la sala de un hospital como culminación de una enfermedad o de un episodio crítico de salud. En todas estas circunstancias que muestran el momento del fallecimiento de una persona hay matices y regulaciones simbólicas que se deben cuidar para no inducir en el espectador una serie de comportamientos cuyas consecuencias no estamos en condiciones de prever: el suicidio no debe presentarse como una solución válida a los dilemas existenciales, el asesinato no puede quedar justificado y la muerte natural requiere acompañamiento y piedad, antes que largos discursos explicativos. En otro orden, la muerte como final se experimenta en el cierre de cada temporada de una serie o en la conclusión de una telenovela, y nos prepara para una metalectura de su significado existencial.

Es probable que la naturalización que ha logrado la televisión de muchos de esos procesos, 
descubra que nos hemos convertido en seres ingenuos e incapaces de criticar la virtualidad audiovisual en la que estamos reclusos. ¿Qué y quiénes son en verdad los que nos rodean? Responder a esta pregunta conduce, pues, a la imperativa necesidad de reconocer al "otro" -no importa si es a través de la distancia mediática o de la inmediatez física- como un ser con quien compartimos una identidad fundamental, aún en las diferencias. Las prácticas comunicativas éticas tratan de garantizar que el camino hacia los demás permanezca abierto y disponible.

\section{Principios para una ética de la ficción televisiva}

Según el consenso académico, la ética tiene como su principal pretensión "hacer una prescripción de los actos humanos, en función de principios y con bases racionales, a partir de los cuales se puede considerar un cuadro de valores y de normas de conducta que dirijan los mismos actos" (Mota Rodríguez, 2006, p. 43). En esa articulación de guías para la acción, los principios se localizan en el más alto grado de abstracción por lo cual, si bien no pierden foco en lo concreto, logran un grado de generalidad que potencia su capacidad normativa.

De lo dicho se infiere que los mismos principios pueden dar origen a diversas pautas y estrategias para orientar nuestros actos. Eso es lo que los hace interesantes y útiles, una vez que hemos desechado el rigorismo de criterios extrínsecos como recetas para la conducción de la vida moral. La ficción audiovisual puede brindar, en este sentido, un campo propicio para la consideración de los principios como las coordenadas para moverse en la creación y producción de los relatos. No se trata, entonces, de elaborar un decálogo de mandatos a cumplir sino de iluminar ciertas áreas de compromiso o responsabilidad para que los elementos narrativos y dramáticos efectivamente sirvan a un propósito de mejora moral en los receptores.

Esta mirada reclama, en primer lugar, la vigencia plena del "Principio de no instrumentalización" que consiste en "tratar a las personas como fines en sí mismas" (Wellmer, 1994, p. 24) para evitar degradarlas en medios usufructuables. Ya vimos que la búsqueda de rentabilidad mediante la captación de audiencias masivas atentaba contra este principio y vulneraba la posibilidad de dirigirse a la inteligencia a partir de la búsqueda de una seducción sólo sensitiva y emocional. Silverstone (2010) propone, además, la introducción de un "Principio de Hospitalidad" para recibir y dar lugar a los que son diferentes y otorgarles derecho a la representación en el seno de la mediatización global. Por este principio tomamos conciencia de la existencia del "otro" en una doble aparición: en la multitud anónima de la audiencia y en la figuración simbólicodramática de los personajes de ficción.

$\mathrm{Si}$, como sostiene Ricoeur, narrar es juzgar (2000, p. 204), entonces la necesidad de incluir en la pantalla "una visión que rompe estigmas respecto de las minorías étnicas o las diferencias culturales, una visión que nos acerca con matices y riqueza a lo real y a las causas de la violencia" (Gozálvez, 2004, p. 227) significaría una ampliación del horizonte de representación del "otro". No hay que olvidar que las ficciones televisivas nos conmueven, antes que por las argumentaciones racionales, por el contagio sentimental o emotivo. 
En el relato de una historia de vida siempre hay una perspectiva desde la que se narra, siempre hay uno o varios personajes que nos invitan con sutileza a meternos en su piel y a percibir desde sus valores y sus circunstancias concretas las vivencias de que son objeto (Gozálvez, 2004, p. 191).

Por estos motivos, no resulta extraño que el melodrama latinoamericano decantado en las telenovelas alcance esa condición ambivalente de expresión catártica y de consolidación identitaria. Así, más que un género audiovisual, la telenovela se erige en "una matriz cultural que alimenta el reconocimiento popular en la cultura de masas" (Martín Barbero-Rey, 1999, p. 125) y por ello puede, sin proponérselo, influir en las prácticas sociales concretas. Títulos como Cristal o Simplemente María, fueron el disparador para que en Venezuela y España se incrementaran las consultas médicas por cáncer de mama, o aumentara en Perú la matrícula en cursos de alfabetización y de costura, respectivamente (Mazziotti, 1996, p. 11). Con mayor énfasis, la trama no tiene que dejar lugar a dudas respecto de quién es cada uno y el reconocimiento público de esa verdad tiene muchas veces el carácter de una reparación justiciera (Mazziotti, 1996, p. 15): saber quién soy y de dónde vengo irrumpen en el argumento de Televisión por la identidad, un conjunto de tres unitarios emitidos por Telefé en 2007 y cuyo antecedente fue la telenovela Montecristo (2006) en la que se trataba el robo de bebés por parte de una organización delictiva de adopciones encubiertas, pero que remitía a una relectura sobre sucesos similares durante la última dictadura militar.

Este análisis nos lleva a la postulación de un tercer principio, el "Principio de Credibilidad" que regula el aporte que hacen a la textualidad de la ficción televisiva aquellas "historias basadas en los valores sociales vigentes, moralmente coherentes, y con personajes, tramas y situaciones creíbles" (García de Castro, 2002, p. 230). Aquí, podríamos afirmar, el orden es ficticio pero los componentes son reales. Como el lector ya imagina, en estos casos es necesario agudizar la atención para no comunicar esquemas morales que fácilmente podrían asumirse como aceptables en la medida en que se ocultan tras la veracidad de los elementos descriptivos próximos a la audiencia. Esta situación tiende a complicarse cuando entran en juego las categorías de bien y mal, y se las incorpora como esencialmente relativas. "El malvado de carácter plano no debe ganar, pero el pícaro puede vencer al mafioso; o el delincuente redimido, al poder. Incluso el peor de los malvados merece vencer, si es más inteligente que los ciudadanos mediocres, o no especialmente peor -estéticamente hablando-que ellos" (Cano, 1999, p. 27).

Ese relativismo ético que al principio puede suscitar simpatía, ligada a la originalidad del diseño argumental (como, por ejemplo, en las películas de W. Allen, Crimes and Misdemeanors y Match Point, en que los resultados aberrantes de acciones malvadas, finalmente, son incorporadas a la experiencia del protagonista quien queda impune y sin complejos de culpabilidad), termina convirtiéndose, con la reiteración, en una inversión sofisticada de los cánones naturales de la decencia y la integridad.

Sin embargo, no nos debemos engañar:

lo que le gusta al público de hoy, como a los atenienses del siglo IV antes de Cristo, es que los personajes inviertan su suerte para bien: es decir, que los buenos empiecen mal y acaben en situación dichosa, mientras que los malos empiecen bien y acaben derrotados (Cano, 1999, p. 27). 
Esa es una de las causas de que en las telenovelas se reiteren los premios y los castigos, la redención o el perdón, todas ellas formas de redirigir la trama hacia el óptimo moral que conviene al argumento sin dejar por ello de "de sorprender, de emocionar cíclicamente y mantener en crescendo la expectación del auditorio" (Cano, 1999, p. 88).

Por otra parte, la inclusión de personajes comunes y situaciones familiares en las novelas, emotivamente conectadas con el espectador, ayuda a fidelizar a la audiencia volviéndola protagonista de las historias.

Algo similar sucede con los programas diseñados para adolescentes, en los que el serial televisivo les brinda la oportunidad de reflexionar sobre la cuestión de las relaciones interpersonales, el amor, la influencia de los padres, etc., y "de implicarse en debates morales acerca de la validez moral de los comportamientos de los personajes” (Montero Rivero, 2006, p. 117). De ahí la importancia de discutir los criterios de producción de los guiones, y la dirección y edición de las imágenes, para que la autoridad que confiere el medio no distorsione la prudencia y la racionalidad ética a fuerza de mostrar exageraciones o soluciones heroicas -o incluso disparatadas- que son atractivas para ese segmento de la población.

Un caso particular encontramos en aquellas telenovelas en las que luego del fallecimiento de uno de los protagonistas o familiar, un niño continúa viendo y dialogando con él, aunque permanezca invisible para los demás. Este recurso ha sido objetado numerosas veces por psicólogos y especialistas en familia pues crea una confusión grave en torno al sentido del duelo y a la misma valoración de la vida.

Otro principio que ayuda a lograr el autodominio audiovisual es el "Principio de Tolerancia" gracias al cual tenderíamos a controlar la hiper-representación de ciertos grupos o de ciertas opiniones minoritarias, que generalmente coinciden con las sostenidas por el entorno profesional de la televisión o el Establishment artístico-mediático. Es habitual que los relatos televisivos propongan escenas modélicas en las que los personajes resuelven un conflicto de acuerdo con las pautas aceptadas por un imaginario consenso social que, en rigor, sólo marca la tabla valorativa del star-system local. Esta deformación de la mirada sobre cuestiones tan controversiales como el aborto, o la eutanasia, introduce sutiles cambios de significado o de apreciación que son absorbidos por el público en dosis edulcoradas por las continuas apelaciones a las pulsiones afectivas. Una sabia aplicación del "Principio de Tolerancia" también evitaría «normalizar» lo que la sociedad considera marginal o problematizar lo que se supone normal (Fernández Pedemonte, 2001). Es evidente que aquí empleamos la noción de tolerancia en un sentido paradójico pues nos referimos a la aceptación de valores extendidos en la sociedad y no a la defensa de una microcultura sostenida sobre la inducción realizada entre amigos del ambiente. Sólo con el cumplimiento de ciertos mínimos morales - expresados por los principios que he mencionado- será posible iniciar en la ficción televisiva una etapa compartida de mayor compromiso en la comunicación del bien, la verdad y la belleza. 


\section{Notas}

1. Con respecto a esta cuestión conviene consultar el dossier central del número 84 de la revista Telos. Cuadernos de Comunicación e Innovación, editada por Fundación Telefónica, que está dedicado a los "Contenidos digitales para la nueva televisión”. Allí se afirma que más del 30\% de la población europea ve la televisión a través de Internet y el 29\% de los norteamericanos utiliza para ello una "cross platform" en la que interactúan el móvil, el digital video recorder (DVR) o el VOD. Datos disponibles on line en: http://sociedadinformacion.fundacion.telefonica.com/ DYC/TELOSonline/REVISTA/Presentacin/seccion=1263\&idioma=es_ES.do

2. Cfr. Salomón (2010, p. 92): "En los países epicéntricos las masas no necesitan imaginar los objetos que usan y consumen y al contrario, en los países pobres las masas deben imaginar los objetos que desean usar y consumir. El detalle se inicia en que las imágenes en calidad de figuras imaginativas, y los propios objetos y personajes son creados en unos países y se difunden y se trasladan hacia los otros".

3. En español se publicó con el título Antropología Filosófica (México, F. C. E. , 1977).

\section{Referencias Bibliográficas}

Barker, C. (2003). Televisión, globalización e identidades culturales. Barcelona: Paidós.

Cano, P. (1999). De Aristóteles a Woody Allen - Poética y retórica para cine y televisión. Barcelona: Gedisa.

Casares,J.(1975).Diccionario Ideológico dela Lengua Castellana. Barcelona:Editorial Gustavo Gili.

Cassirer, E. (1971). Filosofía de las formas simbólicas. $3^{\circ}$ T. México: Fondo de Cultura Económica. (1945) [1944]. Antropología filosófica. México: Fondo de Cultura Económica.

Castells, M. (1999). La era de la información - Economía, sociedad y cultural, Vol. II. El poder de la identidad. Madrid: Siglo XXI Editores.

Cortés, J. (1999). La estrategia de la seducción - La programación en la neotelevisión. Pamplona: EUNSA.

Cortina, A. (2004). Ciudadanía activa en una sociedad mediática. En Conill, J. y Gozálvez, V. (Ed.) Ética de los Medios. Barcelona: Gedisa.

Carcía de Castro, M. (2002). La ficción televisiva popular - Una evolución de las series de televisión en España. Barcelona: Gedisa.

Fernández Pedemonte, D. (2001), Ensayos de comunicación con los amigos. Disponible en: http:// damianfernandez.revistatrama.com.ar

GarcíaGalera,M.(2000).Televisión, violenciaeinfancia-elimpactodelosmedios.Barcelona:Gedisa. Gozálvez, V. (2004). Análisis ético-comparativo de los medios. En Conill, J. y Gozálvez, V. (Ed.) Ética de los Medios. Barcelona: Gedisa.

Huertas Bailén, A. (2002). La audiencia investigada. Barcelona: Gedisa.

Joly, M. (2003). La interpretación de la imagen - entre memoria, estereotipo y seducción. Barcelona: Paidós.

Lacalle, C. (2001). El espectador televisivo - los programas de entretenimiento. Barcelona: Gedisa. 
Martín-Barbero, J. y Rey, G. (1999). Los ejercicios del ver - Hegemonía audiovisual y ficción televisiva. Barcelona: Gedisa.

Mazziotti, N. (1996). La industria de la telenovela - La producción de ficción en América Latina. Buenos Aires: Paidós.

Medrano Samaniego, C., Aierbe Barandiaran, A. y Palacios Navarro, S. (2008). La dieta televisiva y los valores: un estudio realizado con adolescentes en la Comunidad Autónoma del País Vasco. Revista Española de Pedagogía, LXVI (239), 65-84.

Montero Rivero, Y. (2006). Televisión, valores y adolescencia, Barcelona: Gedisa.

Mota Rodríguez, A. (2006). Ética analógica: una lectura hermenéutico-analógica de la ética y sus principios. Analogía filosófica, México: Número especial 19.

Nichols, B. (1997). La representación de la realidad - Cuestiones y conceptos sobre el documental. Barcelona: Paidós.

Peñamarín, C. (2005). Ficción televisiva y pensamiento narrativo. Fragmentos de Cultura, Uni versidade Catolica de Goias, Goiania, 15 (2), 339-354.

Rancière,J.(2005).Lafábulacinematográfica-Reflexionessobrelaficciónenelcine.Barcelona:Paidós. Revista Telos, número 84. Cuadernos de Comunicación e Innovación. Fundación Telefónica. Disponible en: http://sociedadinformacion.fundacion.telefonica.com/DYC/TELOSonline/RE VISTA/Presentacin/seccion=1263\&idioma $=$ es_ES.do

Ricoeur, P. (2000). Del texto a la realidad. Buenos Aires: FCE.

Salerno, G. (2007). Rigorismo y pluralidad de principios en ética. Anuario Filosófico, Pamplona, XL (3), 697-717.

Salomon, C. (2010). El Tecnoexistencialismo. Mar del Plata: Ediciones Suarez.

Schaeffer, J.-M (1999). Pourquoi la fiction? Paris: Seuil. Citado en Peñamarín, C. Ficción televisiva y pensamiento narrativo en Fragmentos de Cultura, Universidade Catolica de Goias, Goiania, 15 (2), 339-354.

Simmel, G. (2003). La ley individual y otros escritos. Barcelona: Paidós.

Sobchack, V. (1984). Inscribing ethical space: ten propositions on death, representation and documentary. Quarterly Review of Film Studies, 9 (4), 283-300. Citado en

Wellmer, A. (1994). Ética y Diálogo, elementos del juicio moral en Kant y en la ética del discurso. Barcelona: Anthropos/Universidad Autónoma Metropolitana.

Summary: The overview of television fiction justified to talk about it in terms of moral perplexity and valuation. However, despite the enormous variation of approaches and perspectives on human problems that are presented on screens, almost all share the style of a high emotive commitment and a low demand of criticism. Renewing a moral perspective, therefore, requires awareness of the high incidence of models on audiovisual stories to incorporate into its creation, script, editing and production, principles capable of raising the liability profile of these products. So the principles of no Instrumentation, Hospitality and Tolerance appear as the possible ways to start improving the ethical standards of programming.

Key words: credibility - ethics - Fiction - hospitality - instrumentation - principles - televisiontolerance. 
Resumo: O panorama geral da ficção televisiva justifica que se fale dela em termos de perplexidade moral e valorativa. No entanto, a pesar da enorme dispersão de enfoques e miradas sobre os problemas humanos que se expõem nas telas, casi todos compartilham o estilo de um alto compromisso emotivo e pouca demanda crítica.

Uma perspectiva moral renovadora requere, porém, ter conciência da alta incidência dos modelos presentes nos relatos audiovisuais para incorporar em sua criação, roteiro, edição e produção, os princípios capazes de elevar a responsabilidade sobre o prerfil desses produtos. Assim, os Princípios de não Instrumentizalização, de Hospitalidade, de Credibilidade e de Tolerância aparecem como os caminhos possíveis para comezar a melhorar o nível ético da programação

Palavras chave: credibilidade - ética - Ficção - hospitalidade - instrumentalização - pincípios - televisão - tolerância. 